\title{
Evaluation of NFC-Guidable System to Manage Polypharmacy in Elderly Patients
}

\author{
Khalid Alzahrani $^{1, *}$ and Mrim Alnfiai ${ }^{2}$ \\ ${ }^{1}$ Department of Clinical Laboratories Sciences, College of Applied Medical Sciences, Taif University, P.O. Box 11099, Taif, 21944, \\ Saudi Arabia \\ ${ }^{2}$ Department of Information Technology, College of Computers and Information Technology, Taif University, Taif P.O. Box 11099, \\ Taif, 21944, Saudi Arabia \\ *Corresponding Author: Khalid Alzahrani. Email: Ak.jamaan@tu.edu.sa \\ Received: 31 May 2021; Accepted: 12 July 2021
}

\begin{abstract}
A complete and thorough understanding by patients of their prescriptions is one of the most critical components of a successful treatment journey. Being unfamiliar with the intricacies of prescribed medication can cause serious health risks due to not adhering to prescription instructions or noting potential drug interactions, which can lead to life-threatening injuries. Pharmacists face communication barriers (including non-English speaking patients), lack of time, lack of knowledge, workload, and frequent interruption when dispensing medicines often preventing them from providing the necessary guidance to their patients. To minimize this risk, an NFC-Guidable polypharmacy system was developed integrating Near Field Technology (NFC) into prescription packages. The intention being, to automate prescription identification for elderly patients in hospitals and primary health care (PHC) centers where Arabic is their native language and patients have five or more prescriptions at a time. The system provides prescription information such as name, expiration date based on the Islamic calendar, appropriate dosage, the correct time for a dose, contraindication, and other relevant instructions in Arabic. The objectives of the system are to improve patient safety and enhance the quality of prescription dispensing for elderly and non-English speaking patients. An evaluation study with polypharmacy elderly patients and pharmacists is conducted to understand the perception and acceptance of the system by both groups. The strengths and weaknesses of the system as well as suggestions for improvement from participants were also gathered. The study results indicate that the system helps patients to avoid misuse of sensitive medication and authenticates their prescribed prescription drugs before taking them. The system also assists pharmacists in improving the efficiency of dispensing medication and streamline processes. Overall, the application was well received by both patients and pharmacists. Thus, NFC technology should be integrated into the healthcare sector to overcome language barriers, the lack of specialized medication labels for illiterate or patients with sight constraints as well as unreasonable expectations placed on pharmacists.
\end{abstract}

Keywords: NFC; health; elder patients; pharmacists; language

This work is licensed under a Creative Commons Attribution 4.0 International License, which permits unrestricted use, distribution, and reproduction in any medium, provided the original work is properly cited. 


\section{Introduction}

As noted by the United Nations [1], the world's population is rapidly aging and nearly every country in the world is experiencing a growth in both the number and proportion of older persons. Population aging is not only straining global healthcare systems, but it is also impacting this vulnerable group as they learn to adapt to the challenges of getting older. The elderly population contends with numerous medical ailments, which can not only mean several trips to varying doctors but also entails multiple prescriptions. This occurrence of being prescribed at least five different drugs is referred to as polypharmacy and is common as well as a serious trend for elderly patients [2]. Factors contributing to polypharmacy are multiple medical conditions managed by multiple subspecialist physicians, suffering from chronic mental health conditions, and living in a long-term care facility.

For example, an elderly patient suffering from common age-related medical conditions like hypertension, diabetes, osteoporosis, osteoarthritis, and chronic obstructive pulmonary disease (COPD) is prescribed 12 separate medications [3]. It is estimated that $40 \%$ of elderly individuals are affected by two or more chronic diseases [4] and elderly diabetic patients are at a much greater risk of receiving polypharmacy than individuals suffering from other illnesses [3]. Adding additional concern, globally, over $46 \%$ of the elderly have disabilities, and approximately 250 million people 60 years old and over have moderate to severe disability [5].

The more elderly receiving polypharmacy means a greater chance of tragedy and is viewed as a prescription safety issue. Polypharmacy is associated with potential consequences such as the increased risk of adverse drug-to-drug interactions, increased prescription cost, medication nonadherence, and decreased functional capacity [4]. In fact, the potential for accidental overdose increases when an individual regularly takes five or more medications [6-7]. In a study investigating polypharmacy in Saudi Arabia, Salih et al. [8] reported that $89 \%$ of elderly outpatients experienced polypharmacy, and only $20 \%$ of patients adhere to prescribed medications. Non-adherence to prescribed medication can preclude therapeutic outcomes and waste healthcare resources [9]. In diabetic patients, frequently missing prescription doses can be increasingly dangerous by lowering the recommended drug level causing suboptimal glucose control [10]. As a result, superfluous titration in dosage by the physician can lead to an increased risk of both hypoglycemic and hyperglycemic episodes resulting in detrimental effects [10].

Non-adherence to prescribed medication instructions is reportedly due to confusion regarding the drugs, their correct dosage, and forgetting to take a dose. Any one of these circumstances can lead to severe consequences such as hospitalization [11]. To avoid the worst-case scenario, patients usually adopt approaches like using pillboxes, writing a note on the medicine bottle, and having the drug with their meal or activity to help manage them correctly [12-14]. Having clear prescription information and management helps patients to better comply with physician instructions and minimize the risk of facing serious consequences. Researchers point out that educating patients about their prescriptions leads to higher compliance rates and increased overall patient satisfaction [15]. This is despite the Prescribing Information (PI) being included with the prescription with the sole purpose to inform patients about their medications' appropriate usage, dosage, and side effects [16]. Although, it has been pointed out that this leaflet can be difficult to read by older patients with poor eyesight and non-native English speakers. Typically, pharmacists consider this and try to inform patients of their own accord. However, elderly patients might forget or get confused with various medications due to the overwhelming cognitive load. Thus, developing an accessible tool that uses both a patient's preferred language and a simplified description of PI content would be beneficial and minimize the elderly population's level of risk. And 21st-century technology is ready to meet the challenge; several smart applications have been developed to remind patients to take their medicine [17-24]. Additional applications have implemented the QR code technology sector to assist patients and enhance their safety while taking medication [25-27]. However, 
scanning a QR code requires some technical knowledge requiring patients to open a smartphone camera and precisely direct and position the camera on the QR symbol [28].

To overcome these limitations, Near Field Communication (NFC) technology has proven to be more accessible for older patients having little experience with smartphone devices. This paper describes the design and preliminary evaluation of a newly developed NFC-Guidable system to manage elderly diabetic patient prescriptions to mitigate both user error and inherent risk.

\section{Related Work}

NFC technology has been implemented in several areas of healthcare management. For example, Sethia et al. [29] proposed using Android-based mobile devices integrated with NFC technology and Bluetooth interfaces to store credentials and secure data for health record management through a kind of digital health card. The system uses three NFC communication modes: reader/writer operating mode, peer-topeer mode, and card emulation mode. Meanwhile, Yoon et al. [30] proposed an NFC medication management system for elderly patients. In this system, an NFC-based medication bottle cap and smartphone application program are integrated to sound an alarm reminding the patient to take their prescribed dose. The concept is built upon Apex Medical Corporation's medication organizer that has a built-in LED screen and timer as well as Vitality's GlowCap, a pill bottle with a built-in wireless reminder alarm. It has not yet been tested with an elderly patient sample.

Razm et al. [31] developed an infrastructure to be used in the development of mobile healthcare systems referred to as $\mathrm{M}$-health. These $\mathrm{M}$-health applications are projected to minimize healthcare costs and improve the quality of patient care. By utilizing NFC technology, the proposed system uses mobile devices that are connected to wireless communication technology to securely provide on-demand patient information by hospitals with a focus on emergency rooms and intensive care units where time is critical. The authors explain that this NPC technology can be utilized either inside or outside the body. A mobile device such as a smartphone would store electronic health records, or an implanted RFID device would also wirelessly communicate the patient's medical history. However, the proposed architecture has yet to be applied or tested.

Another NFC-based healthcare system developed by Fontecha et al. [32], combined NFC technology with touch interaction to help nursing students administer medication, clinical tests, and monitor patient vital signs with simple patient-nurse interaction. This system can only be used within the hospital and does not provide support to the patient once released. A prototype has been evaluated by two nursing schools.

While NFC technology has been aiding healthcare workers in some ways, the focus has been less on the patient's welfare and more on facilitating patient care. Of specific interest is the lack of NFC technology used to manage polypharmacy in elderly diabetic patients. Additionally, the ability afforded by NFC technology to provide prescription information in a patient's native language has yet to be studied. Existing systems are also in need of being evaluated by those that would be using the proposed applications for ease of use and overall benefit.

The specific objectives are to:

- Garner patient feedback about the NFC-Guidable polypharmacy system.

- Identify pharmacist perception and acceptance of the NFC-Guidable system.

- Identify patient perception and acceptance of the NFC-Guidable system.

- Determine the strengths and weaknesses of the NFC-Guidable polypharmacy system to inform improvements. 
The primary goal of this research is to improve the quality of medical guidance and enable patients to use prescribed medications safely. It also seeks to reduce prescription errors and potential adverse side effects. The secondary goal is to simplify obtaining patient prescription details such as name, expiration date, instructional use, and potential side effects.

\subsection{Materials and Methods}

The NFC-Guidable polypharmacy system is intended to automate prescription guidance and management. It assists patients in recognizing the following:

- Medication name

- Expiration date based on the Islamic calendar

- Correct prescribed dosage

- Specific time to take the medication

- Potential side effects from food interaction or mixing with other medications

- Any additional prescription instructions

Because this study focuses on an Arabic-speaking sample, prescription guidance is provided in Arabic using NFC technology to bridge any language barrier, another advantage of the system.

\subsection{NFC System Design}

The NFC-Guidable polypharmacy system was implemented using a Nexus S Android smartphone device with Android's 8.1.0 version. NFC technology, in the form of digital tags, was used to store prescription information and guidance. As seen in Fig. 1, NFC communication occurs between two NFCcompatible devices. In this case, a smartphone enabled with the NFC-Guidable polypharmacy system and a corresponding NFC tag that is attached to the prescription bottle.

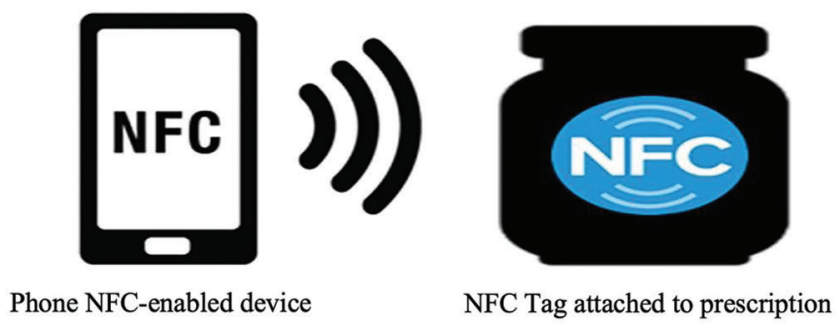

Figure 1: NFC-Guidable polypharmacy system operating mode

The system utilizes the reader/writer operating mode where a smartphone initiates the communication as an active device and can both read from and write to an NFC tag (RFID) on the prescription bottle. This is similar to a QR code, but NFC technology is more secure, requires authentication, and provides customized content.

\subsection{NFC Application Interface}

The NFC-Guidable polypharmacy system has two interfaces, one for pharmacists and the other for patients (see Fig. 2). No technical knowledge is required to use either interface; users simply scan the tag on the pill bottle and receive the prescription information on their smartphone. 

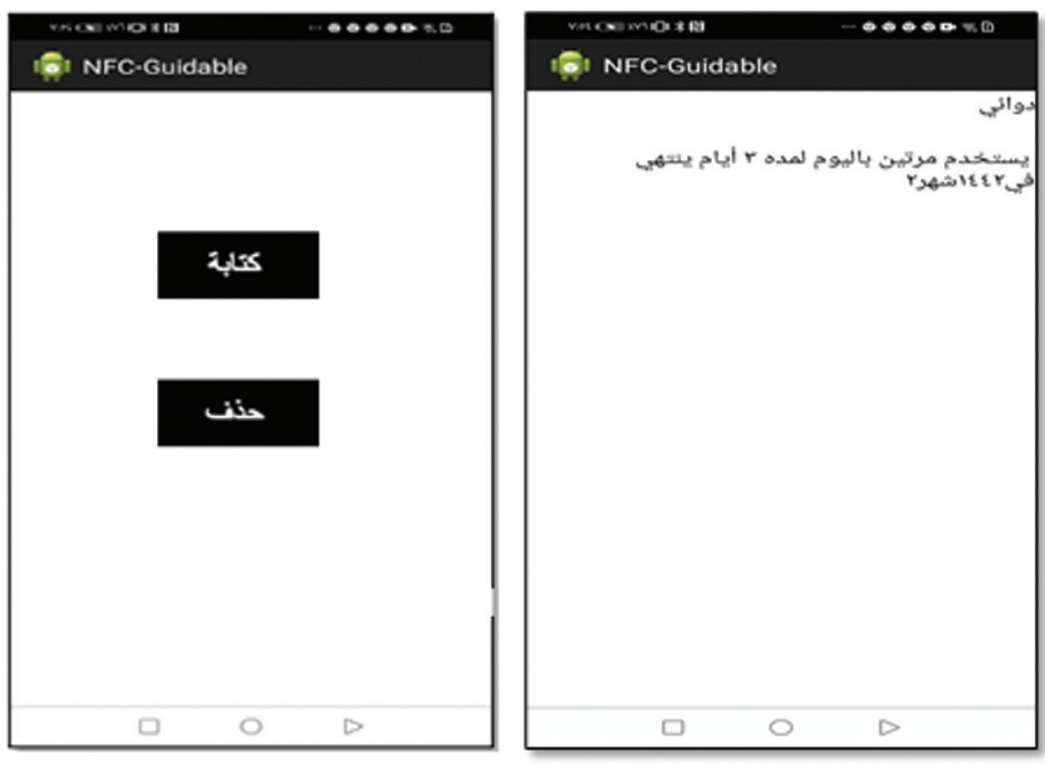

Figure 2: NFC-Guidable system interface

\subsection{NFC Tags}

In the reader/writer mode of the NFC-Guidable polypharmacy system, writing tags are designed for pharmacists. The tag allows them to store relevant prescription information directly in the digital NFC tag that is attached to the prescription bottle. Pharmacists or physicians can determine the content stored within the NFC tag for each medicine. Pertinent information includes the purpose of the medicine, the required dose per day, the time and correct method patients should take the drug, contraindications, and the expiration date. In contrast, reading tags are designed for patients allowing them to retrieve the prescription information using their Android device to scan the pill bottle's NFC tag.

\section{NFC-Guidable Polypharmacy System Evaluation}

\subsection{Usability Testing Design}

To perform the NFC-Guidable polypharmacy system usability test, researchers confirmed patient prescription information with each participant's physicians. Then, NFC tags placed on the prescription bottles were programmed with this data.

Patient participants were asked to use the NFC-Guidable polypharmacy system in their home for six weeks. They were to use their smartphone to read the prescription tag each time they needed to take their medication and/or each time they could not identify a pill bottle. Meanwhile, pharmacists were responsible for writing the prescription information for the attached NFC tag.

The study is organized as follows:

- Participant Pre-questionnaire

- NFC-Guidable Training

- NFC-Guidable Usability Test

- Participant Perception and Acceptance Questionnaires

- Participant Interview Sessions 


\subsection{Procedure}

The researchers sent an email to potential participants containing the study description, objectives, and procedures to the hospital director. The hospital director shared it with pharmacists and physicians who monitor the health of elderly patients. Pharmacists wanting to participate in the study sent an email response and a meeting session was arranged to sign the consent form and collect demographic data as well as train them on how to use the application. The physicians recruited patients that suffer from chronic diseases and have trouble reading the fine print. For the initial patient visit, the participating pharmacists and researchers explained the study to the patients who then signed the consent form. Then, the researchers collected demographic data from the patients including age, gender, health status, number of prescribed medicines. Meanwhile, the pharmacists recorded each patient's prescription information using the developed mobile application. Researchers followed up by explaining to the patients the usage of the application and answered any remaining questions. After the study, participants answered perception and acceptance questionnaires and were interviewed individually. Participation was voluntary in all phases of the study. Participants were also informed that they may withdraw from the study at any time. No private or identifying information was collected and the study was approved by Taif University.

\subsection{Participants}

Participants for the usability test included 9 elderly patients and 7 pharmacists. Both groups were recruited from the Alsahan Hospital and AL-Dar Alhamra Center in Taif, Saudi Arabia. Patient participants suffer from chronic disease and take more than three medications. They also have limited knowledge of smartphone technology. Inferential statistics were gathered at the beginning of the research including demographic data for each group. Patient participants were asked about their age, gender, health status, the number of medications prescribed to them, and their level of technical experience (Tab. 1). Pharmacist participants were asked about their gender, years of experience with patients, and level of technical knowledge (Tab. 2).

Table 1: Patient demographic data

\begin{tabular}{|c|c|c|c|c|c|}
\hline $\begin{array}{l}\text { Patient } \\
\text { number }\end{array}$ & Gender & Age & Health status & $\begin{array}{l}\text { Number of } \\
\text { prescribed } \\
\text { medicines }\end{array}$ & $\begin{array}{l}\text { Technical } \\
\text { experience }\end{array}$ \\
\hline P1 & Male & 92 & Diabetes and high blood pressure & 7 & No experience \\
\hline $\mathrm{P} 2$ & Female & 71 & Low blood pressure and high heart rate & 5 & \\
\hline P3 & Female & 76 & $\begin{array}{l}\text { High blood pressure, diabetes, and kidney } \\
\text { inflammation }\end{array}$ & 7 & \\
\hline P4 & Female & 70 & High blood pressure, diabetes, and heart disease & 7 & \\
\hline P5 & Male & 84 & Kidney infections, high blood pressure, diabetes & 6 & \\
\hline P6 & Female & 80 & Cholesterol and diabetes & 3 & \\
\hline P7 & Female & 75 & Diabetes and high blood pressure & 5 & \\
\hline P8 & Female & 71 & Diabetes and high blood pressure & 5 & \\
\hline P9 & Male & 91 & A stroke, high blood pressure, and high cholesterol & 7 & \\
\hline
\end{tabular}


Table 2: Pharmacist demographic data

\begin{tabular}{llll}
\hline Pharmacist number & Gender & Length of experience & Technical experience \\
\hline Pharm1 & Male & 3 years & Expert \\
Pharm2 & Male & 7 years & Moderate \\
Pharm3 & Male & 12 years & Moderate \\
Pharm4 & Male & 7 years & Moderate \\
Pharm5 & Male & 1 year & Expert \\
Pharm6 & Male & 2 years & Expert \\
Pharm7 & Male & 1 year & Expert \\
\hline
\end{tabular}

\subsection{Participant Pre-Questionnaire}

In the pre-questionnaire, in addition to demographic information, patient-participants were asked to answer a series of questions regarding their experience with prescription management, appropriate use and identification, and physician guidance as well as dosage instructions. Pharmacist participants, in addition to demographic information, were questioned about how prepared they feel their patients are to correctly read prescription labels provided in English as well as to properly follow medical guidance.

\subsection{NFC-Guidable Polypharmacy System Training}

During the NFC-Guidable polypharmacy system training researchers explained to participants how to use the application. The participants were trained to use the NFC-Guidable tag system under supervision to first familiarize themselves with the application. The single training session was 15 min in duration.

\subsection{Participant Perception and Acceptance Questionnaires}

Upon completion of the six-week usability test, each group of participants was asked to complete both perception and acceptance questionnaires. The perception and acceptance surveys were developed with the Holden et al. [33] instrument framework, which uses cross-sectional survey data to determine all variables for perceptions and acceptance. Using the review of NFC technology literature, the surveys were adapted to meet the needs of the current study.

\subsection{Participant Interview Sessions}

Following the perception and acceptance questionnaires, both participant groups were interviewed. The intention is to learn more about the software's strengths, weaknesses, appropriateness of tag information, and overall impressions while using the application.

Pharmacists were asked:

1. Does the system improve how prescription information is provided to patients?

2. Does the system simplify the process for a pharmacist when explaining medications to the patient?

3. From your perspective, what are the system's strengths and limitations?

4. From your perspective, do you have any suggestions for improving the system? 
Patients were asked:

1. From your perspective, what are the system's strengths and limitations?

2. From your perspective, do you have any suggestions for improving the system?

\section{Results and Discussion}

The following identifies the findings of the participant pre-questionnaire, NFC-Guidable polypharmacy system training, NFC-Guidable polypharmacy system usability testing, participant perception and acceptance questionnaires, and subsequent interview sessions.

\subsection{Pre-Questionnaire Results}

The pre-questionnaire shows that all patient participants take anywhere from 3 to 7 medications regularly because they suffer from chronic diseases such as high blood pressure, diabetes, and heart disease. They have depended on one family member to manage and identify their medications in the past, causing hardship for the family and leaving room for error should the responsible party change. Thus, they tried to use a pillbox organizer to manage medications, but at times the patients reported getting confused and possibly making an error. None of the patient participants check the expiration date of their prescriptions, despite potential harmful effects, because they are formatted in the Gregorian style rather than using the Islamic calendar. Another obstacle described by patient participants is critical information being provided in English, which is not their native tongue. One participant explained that sometimes they had to ask their families to translate the name of the medicine and identify the correct dosage. A few remarked that they also ask the pharmacist for help when they have questions about their medication or cannot read the provided information. For example, patient 5 stated that "I have difficulty understanding the prescription. In particular, for periodic medicine, I do not understand the written abbreviation on the medicine package, and I do not know how many times I can use it every day. My son sometimes visits the hospital to confirm the instructions for my medicine."

The pre-questionnaire indicates that pharmacist participants face difficulties when fulfilling prescriptions for elderly patients that regularly take multiple medications. The challenge increases when the patient requires more than 5 drugs because they easily become confused and overwhelmed. Pharmacist 3 stated that, "I face difficulty in describing the prescriptions for elder people who have hearing impairment" while pharmacist 5 reported that, "I am always worried about elder people who have to take more than 3 drugs and they do not have a young person who accompanies them during the visit; they usually get overloaded and confused about the prescription for each medicine." Pharmacist 2 noted that, "one of the key issues I have faced was explaining the prescription to a patient who does not speak my language." And Pharmacist 1 stated that, "if the drug brand changed, old patients who identify their medications by the box color get confused and usually use the medicine incorrectly."

All pharmacists explained that they use verbal instruction with patients informing them of prescription proper use. However, pharmacist participants also reported that they do not inform patients of the expiration date, but ensure it is recorded on the bottle.

\subsection{NFC-Guidable System Perception and Acceptance Results}

The perception survey used in this study for pharmacist participants evaluated five NFC-Guidable related factors [33], which are (1) ease of use, (2) usefulness for the job, (3) social influence from nonspecific others to use the NFC-Guidable system (4) training, (5) usefulness for patient care, and (6) social influence from patients/families (Tab. 3). 
Table 3: Pharmacists' perceptions of NFC-Guidable system

\begin{tabular}{|c|c|c|c|c|c|c|c|}
\hline \multirow[t]{3}{*}{ Factors } & \multicolumn{7}{|c|}{ Response frequencies $(\%)$ on $0-6$ scale } \\
\hline & 0 & 1 & 2 & 3 & 4 & 5 & 6 \\
\hline & $\begin{array}{l}\text { Not } \\
\text { at all }\end{array}$ & $\begin{array}{l}\text { A } \\
\text { little }\end{array}$ & Some & $\begin{array}{l}\text { Moderate } \\
\text { amount }\end{array}$ & $\begin{array}{l}\text { Pretty } \\
\text { much }\end{array}$ & $\begin{array}{l}\text { Quite } \\
\text { a lot }\end{array}$ & $\begin{array}{l}\text { A great } \\
\text { deal }\end{array}$ \\
\hline \multicolumn{8}{|l|}{ Perceived ease of use (PEOU) } \\
\hline Clear and understandable & 0 & 0 & 0 & 0 & 1 & 4 & 2 \\
\hline Easy to use & 0 & 0 & 0 & 0 & 0 & 4 & 3 \\
\hline Requires a lot of mental effort & 4 & 1 & 2 & 0 & 0 & 0 & 0 \\
\hline Easy to get it to do what I want & 0 & 0 & 0 & 1 & 0 & 2 & 4 \\
\hline \multicolumn{8}{|l|}{ Perceived usefulness, generic (PU) } \\
\hline Improve job performance & 0 & 0 & 0 & 0 & 0 & 3 & 4 \\
\hline Increases productivity & 0 & 0 & 0 & 0 & 0 & 4 & 3 \\
\hline Enhances effectiveness in job & 0 & 0 & 0 & 0 & 1 & 3 & 3 \\
\hline Useful in job & 0 & 0 & 0 & 0 & 0 & 2 & 5 \\
\hline \multicolumn{8}{|c|}{ Perceptions of NFC-Guidable training (TRAINING) } \\
\hline Amount received & 0 & 0 & 0 & 2 & 2 & 1 & 2 \\
\hline Usefulness of training & 0 & 0 & 0 & 0 & 1 & 5 & 1 \\
\hline Completeness of training & 0 & 0 & 0 & 1 & 1 & 3 & 2 \\
\hline How well timed was training & 0 & 0 & 0 & 0 & 2 & 3 & 2 \\
\hline \multicolumn{8}{|c|}{ Perceived Usefulness for Patient Care (PU-PT) } \\
\hline Improves patient care & 0 & 0 & 0 & 0 & 0 & 5 & 2 \\
\hline Reduces likelihood of medication error & 0 & 0 & 0 & 0 & 0 & 4 & 3 \\
\hline Facilitates patient care decision making & 0 & 0 & 0 & 0 & 0 & 4 & 3 \\
\hline Makes caring for patients easier & 0 & 0 & 0 & 0 & 0 & 3 & 4 \\
\hline \multicolumn{8}{|c|}{ Perceived social influence from patient/family (SI-PT) } \\
\hline Patients/families like system & 0 & 0 & 0 & 0 & 0 & 3 & 4 \\
\hline $\begin{array}{l}\text { Patients/families believe system reduces } \\
\text { chances of medication errors }\end{array}$ & 0 & 0 & 0 & 0 & 0 & 2 & 5 \\
\hline $\begin{array}{l}\text { Patients/families believe system is good for } \\
\text { quality patient care }\end{array}$ & 0 & 0 & 0 & 0 & 1 & 1 & 5 \\
\hline $\begin{array}{l}\text { Patients/families appreciate being scanned } \\
\text { before taking medicines }\end{array}$ & 0 & 0 & 0 & 1 & 1 & 1 & 4 \\
\hline
\end{tabular}

Overall, the correlation between pharmacist perception scores was highly positive. Pharmacists rated the NFC-Guidable system as easy to use by Perceived Ease of Use (PEOU) standards (PEOU, mean $=0.96$, $\mathrm{SD}=1.47$ ) (as shown in Fig. 3). Also, 57.1\% of pharmacists found the NFC-Guidable application is clear and understandable. None of the participants reported the NFC-Guidable system was 'not at all,' only 
'a little,' or 'somewhat' easy to use and $57.1 \%$ reported using 'none at all, '14.3\% 'a little,' and $28.6 \%$ 'some" mental effort when using the application (Tab. 3).

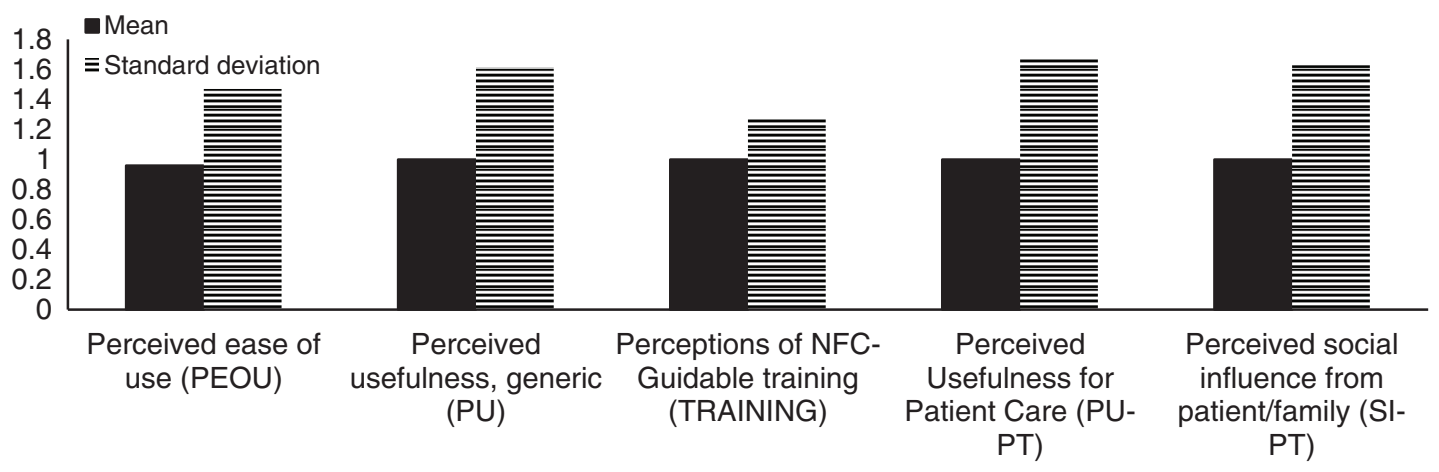

Figure 3: Pharmacists' perceptions mean and standard deviation of NFC-guidable system

Pharmacists rated the NFC-Guidable system as extremely useful for improving job performance (PU, mean $=1, \mathrm{SD}=1.61$ ) (as shown in Fig. 3). None of the participants perceived that the application 'not at all', 'a little' or 'some' improve job performance, increase productivity, enhances effectiveness in job and it is useful in their job. Over $57.1 \%$ perceived that NFC-Guidable system did 'a great deal' and $42.9 \%$ perceived that NFC-Guidable system did 'quite a lot' in improving job performance; 42.9 perceived that NFC-Guidable system did 'A great deal' useful in their job; even larger proportions of pharmacists perceived NFC-Guidable system improving productivity or effectiveness of medication dispensing. Over half the pharmacists perceived that BCMA did 'a quite a lot' make patient care easier, and $42.9 \%$ perceived that the NFC-Guidable system reduced the likelihood of medication error 'A great deal'.

Most participants rated perceptions of NFC-Guidable training more beneficial than not (Training, mean $=1, \mathrm{SD}=1.27$ ) (as shown in Fig. 3). 57.1\% reported that 'quite a lot' training for the NFCGuidable system was useful. Pharmacists' perceptions of the training timing were quite appropriate for $42.9 \%$ and $28.6 \%$ completed the whole training and $42.9 \%$ completed part of the training.

Pharmacists reported that the NFC-Guidable system is useful for patient care (PU-PT, mean $=1, \mathrm{SD}=$ 1.67) (as shown in Fig. 3). 71.1\% responded that the application enhances patient care 'quite a lot' and 57.1\% perceived the application quietly minimized the rate of medication error and facilitated better patient care decision making. $57.1 \%$ also perceived the application as greatly making caring for patients easier.

Pharmacists perceived a very high social influence from patients and family (SI, mean $=1, \mathrm{SD}=1.63$ ) (as shown in Fig. 3). $71.4 \%$ responded 'a great deal' and $28.6 \%$ responded 'quite a lot' of patients and families like the NFC-Guidable system. 100\% responded 'quite a lot' or 'a great deal' that system reduces chances of medication errors, and that $71.4 \%$ the application is effective for quality patient care, $57.1 \%$ perceived those patients appreciated being scanned before medication administration 'a great deal'.

\subsection{Pharmacist Acceptance of NFC-Guidable System}

Tab. 4 displays the pharmacist's responses toward acceptance of the NFC-Guidable system. Pharmacists' intention to utilize the application over moderate (BI, mean $=1, \mathrm{SD}=1.44) .42 .9 \%$ responded that if they have access to the system, they will quietly use it and $57.1 \%$ percent would want to use the application if it were up to them (as shown in Fig. 4). 
Table 4: Pharmacist scores on acceptance responses for individual scale items

\begin{tabular}{|c|c|c|c|c|c|c|c|}
\hline & \multicolumn{7}{|c|}{ Response frequencies $(\%)$ on $0-6$ scale } \\
\hline & 0 & 1 & 2 & 3 & 4 & 5 & 6 \\
\hline & $\begin{array}{l}\text { Not at } \\
\text { all }\end{array}$ & $\begin{array}{l}\text { A } \\
\text { little }\end{array}$ & Some & $\begin{array}{l}\text { Moderate } \\
\text { amount }\end{array}$ & $\begin{array}{l}\text { Pretty } \\
\text { much }\end{array}$ & $\begin{array}{l}\text { Quite a } \\
\text { lot }\end{array}$ & $\begin{array}{l}\text { A great } \\
\text { deal }\end{array}$ \\
\hline \multicolumn{8}{|c|}{ Behavioral intention to use system (BI) } \\
\hline $\begin{array}{l}\text { Intend to use system if I have } \\
\text { access }\end{array}$ & 0 & 0 & 1 & 1 & 2 & 3 & 0 \\
\hline $\begin{array}{l}\text { Predict I will use system if I have } \\
\text { access }\end{array}$ & 0 & 0 & 0 & 2 & 1 & 4 & 0 \\
\hline $\begin{array}{l}\text { Would want to use system if it were } \\
\text { up to me }\end{array}$ & 0 & 0 & 0 & 1 & 1 & 5 & 0 \\
\hline \multicolumn{8}{|l|}{ Satisfaction with system (SATISF) } \\
\hline Satisfied with system & 0 & 0 & 0 & 0 & 0 & 3 & 4 \\
\hline Prefer system to prior process & 0 & 0 & 0 & 0 & 1 & 2 & 5 \\
\hline Dissatisfied with system & 3 & 2 & 2 & 0 & 0 & 0 & 0 \\
\hline Would recommend to a friend & 0 & 0 & 0 & 0 & 2 & 2 & 3 \\
\hline
\end{tabular}

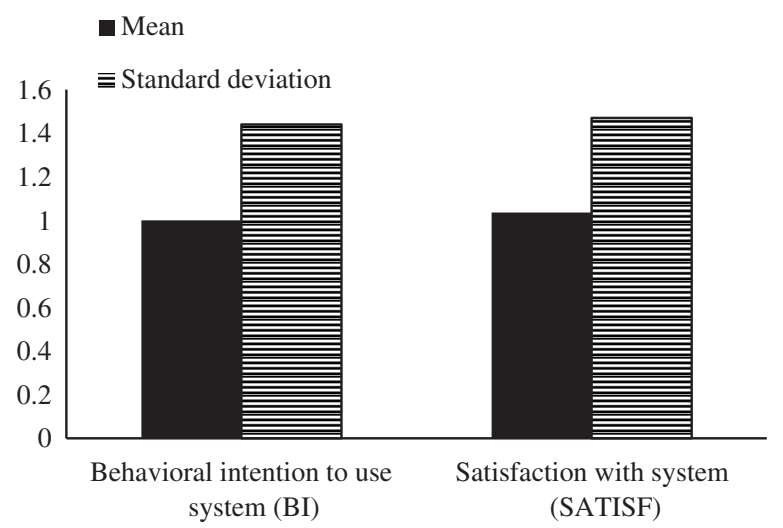

Figure 4: Pharmacists' acceptance responses mean and standard deviation

In addition, the participants' satisfaction with the system was highly positive (SATISF, mean $=1.036$, $\mathrm{SD}=1.47$ ) (as shown in Fig. 4). Over 57.1\% reported that they were satisfied with the application and $71.4 \%$ reported the preference of the system over prior methods. Over $71.4 \%$ reported that they were 'not at all' or 'a little' dissatisfied with the application and $42.9 \%$ percent are willing to recommend this application to friends at other hospitals.

\subsection{Patient Acceptance of NFC-Guidable System}

Tab. 5 displays the patients' responses toward acceptance of the NFC-Guidable system. Patients' intention to utilize the application over moderate (BI, mean 1.2, SD 1.677) (as shown in Fig. 5). Over $77.8 \%$ of patients were intended to use the application if they have access. $55.56 \%$ of respondents said 
the system would help their well-being 'a great deal.' Similarly, 55.56\% of the respondent said they would use the system 'a great deal' if it were up to them.

Table 5: Patients' acceptance of NFC-Guidable system

\begin{tabular}{|c|c|c|c|c|c|c|c|}
\hline & \multicolumn{7}{|c|}{ Response frequencies (\%) on $0-6$ scale } \\
\hline & 0 & 1 & 2 & 3 & 4 & 5 & 6 \\
\hline & $\begin{array}{l}\text { Not at } \\
\text { all }\end{array}$ & $\begin{array}{l}\text { A } \\
\text { little }\end{array}$ & Some & $\begin{array}{l}\text { Moderate } \\
\text { amount }\end{array}$ & $\begin{array}{l}\text { Pretty } \\
\text { much }\end{array}$ & $\begin{array}{l}\text { Quite a } \\
\text { lot }\end{array}$ & $\begin{array}{l}\text { A great } \\
\text { deal }\end{array}$ \\
\hline \multicolumn{8}{|c|}{ Behavioral intention to use system $(\mathrm{BI})(\mathrm{N}=9)$} \\
\hline $\begin{array}{l}\text { Intend to use system, if I have } \\
\text { access }\end{array}$ & 0 & 0 & 0 & 2 & 2 & 1 & 4 \\
\hline $\begin{array}{l}\text { I will use the system, if I have } \\
\text { access }\end{array}$ & 0 & 0 & 0 & 1 & 2 & 1 & 5 \\
\hline $\begin{array}{l}\text { Would want to use system, if it } \\
\text { were up to me }\end{array}$ & 0 & 0 & 0 & 1 & 0 & 3 & 5 \\
\hline \multicolumn{8}{|c|}{ Satisfaction with system (SATISF) $(\mathrm{N}=9)$} \\
\hline Satisfied with system & 0 & 0 & 0 & 1 & 0 & 4 & 4 \\
\hline Prefer system to prior process & 0 & 0 & 1 & 2 & 0 & 2 & 4 \\
\hline Dissatisfied with system & 5 & 3 & 0 & 1 & 0 & 0 & 0 \\
\hline Would recommend to a friend & 0 & 0 & 0 & 1 & 0 & 3 & 5 \\
\hline
\end{tabular}

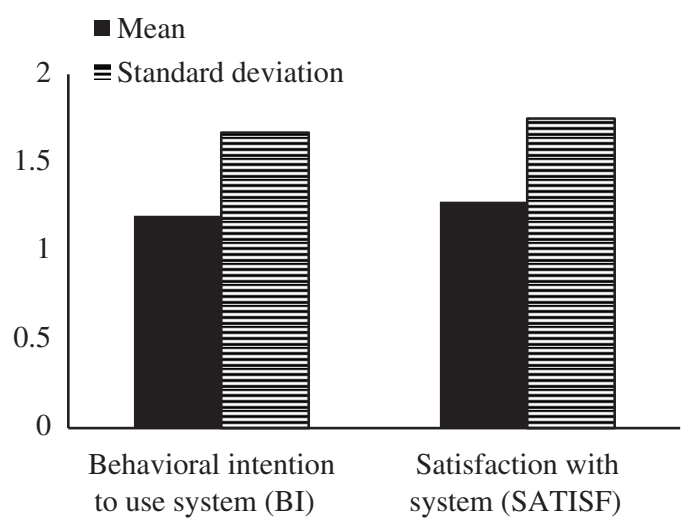

Figure 5: Patients' acceptance responses means and standard deviation

Satisfaction with the NFC-Guidable system was significantly positive (SATISF, mean $=1.28, \mathrm{SD}=1.75$ ) (as shown in Fig. 5). Over $88.89 \%$ reported that they were satisfied with the application and $66.67 \%$ of patients preferred to use the NFC-Guidable application to prior used methods. $88.89 \%$ reported being 'Not at all' or 'a little' dissatisfied with the application. Over half of the participants reported that they would recommend the NFC-Guidable system to friends at another hospital. 


\section{Discussion}

The pre-questionnaire for the pharmacist participants highlights several challenges to prescribing medication to elderly and polypharmacy patients such as language, hearing impairment, illiteracy, and medications of the same name but with different packaging. In addition, most of their patients are dependent on caregivers or family members. They frequently get confused when receiving prescriptions for 3 or more medications. Thus, this technology can make them more independent. The study shows that pharmacists valued the NFC-Guidable system and found it helpful when dispending drugs. Most importantly, pharmacists indicated that they would implement the NFC-Guidable system into their protocols if available.

The NFC-Guidable system is the first application that allows pharmacists to provide prescription information in Arabic while enabling patients to check their prescription information whenever they choose. It is a valuable resource for caregivers who can simply scan the NFC tag attached to the prescription bottle.

The study's patient participants did not have experience with smartphone technology. Despite this, they found the application easy to use and having an accessible interface. They also described the tool as helpful to take their medications more safely. Patients unfamiliar with their medications valued the application and appreciated it as a sort of reminder to take their dose. They also reported that the system helps avoid confusion about how to properly take their medicine.

\subsection{Strengths}

The NFC-Guidable system has several benefits for healthcare in terms of learnability and usability. The key strength of the system is that NFC technology is simple and intuitive. This feature makes the NFCGuidable system fast and easy to operate, where it just requires users to scan the NFC tag to retrieve the stored information. Patient 2 stated that "I could use the application without training." In addition, one of the patients stated that "I can use the application without assistance where I just touch the drug package to know my prescription." Another patient stated that "the application is very informative and highly accurate for medications. It helps identify medicines, but I wish that it reminds me when I should refill medicines." Patient 7 said, "It is a very helpful application for knowledge about medicines and their uses." Patient 5 stated that "it can be used as a reference note for medicine information." Also that, "the application is easy to use, fast and helpful. Most importantly it can be used offline to obtain medical information."

The NFC-Guidable application is effective because it is easy to use, and it reduces the time pharmacists prescribing the medicine usage to patients. It can be an effective alternative method instead of orally describing the prescription or writing it on the drug package. Pharmacists also found that NFC-Guidable application improves patients' care and safety. Another advantage pharmacist reported is that it minimizes the effort that pharmacists provide when describing the medicine usage. Furthermore, pharmacists found the application can speed up the medicine dispensing process and eliminate errors.

Patients stated that the ability to read the NFC tag by smartphone device is very important where users can use their device to read the content of a tag without a need for other equipment. However, not all smartphone devices are capable to read the NFC tags. All these advantages might assist pharmacists and patients to accept the NFC-Guidable application for prescriptions' identifications. Thus, NFC technology has great potential for different applications and services in the healthcare sector.

\subsection{Weaknesses}

A weakness of the NFC technology is that NFC tags come with different storage sizes. If pharmacists want to store a large amount of information, they must pay for additional space, which is expensive [34]. 
Another limitation is that not all smartphone devices are capable of reading NFC technology. Pharmacists reported that preparation the NFC content for each medication tag could be time-consuming as would require preparing it in advance.

\subsection{Suggestions}

Participants provided several suggestions to improve the NFC-Guidable system features. Pharmacists suggested preparing a booklet that has common prescription information on it for most patients to speed up the process of preparing and writing the content on the tag. Also, one pharmacist suggested that preparing the content of the tag should be by the physicians because he stated, "patients trust physicians more than Pharmacists." An important suggestion from pharmacists about the tag content indicates the importance of informing patients about the right time to take drugs and whether before, after, or with a meal.

Patients suggested adding a reminder to notify them when it is time to take their medications. Another suggested adding a feature that determines potential harmful and unsafe combinations of prescribed drugs once a user taps on the prescription bottle.

\section{Conclusion}

In this paper, the NFC smartphone application implemented to provide a medication identification and management service for old patients is described. To improve medication adherence and safety, the NFCGuidable application is developed to help patients and pharmacies, caregivers, and family members automatically identify medications' prescription. This application also helps patients automatically ensure they are taking the right medication.

This application was evaluated with 9 elder patients and 7 pharmacists, and their perception and acceptance of the service were positive. This application can be used by anyone who cannot read English or who has cognitive issues where they quickly forget the given information by pharmacists. The NFCGuidable system improves the quality of filling prescriptions by providing adequate medical information and enhancing medicine guidance and uses. One of the key strengths of the NFC application is that the NFC technology is easy to use by both people who are familiar with technology and who are not. It also can be read by a smartphone very fast. The study highlighted that using NFC improves patient experience while taking medicine.

However, the developed application needs some improvements, such as preparation of the NFC tag content, add other critical features to the app, such as detecting medications interactions and time reminders.

The result has some strengths and limitations. The key strength of the study is that it includes both quantitative and qualitative measures to have a clear overview of patients' perspectives. Also, it covers sample subjects who have similar characteristics including literacy and no experience with smartphone devices. However, the conducted study has some limitations, which prevent the study from being generalizable. The limitations are the study length was short to identify the application strengths and weaknesses, as well as the sample size from pharmacists and patients, was small.

Overall, using NFC application for medication identification and prescription has a potential and it can be considered an effective solution for older patients who use a set of medications. It is also a better solution to assist pharmacists to provide the prescription digitally, which enhances the medicine dispensing process to patients.

In the future, we are planning to improve the features of the NFC-Guidable Tag system to meet users' requirements by preparing the NFC tags contents in advance to eliminate typing errors from the pharmacist's side. There is also a need to conduct a long study to find out whether this type of technology affects the number of patients visiting times as well as the number of calling physician times. We are also planning 
to use other technology like RFID to enhance patients' awareness about their medicine prescription and improve their fallowness of instructions.

Acknowledgement: The authors thank Alsahan Hospital and AL-Dar Alhamra Center for the study participants. This research was supported by a Grant for Scientific Research from Taif University, kingdom of Saudi Arabia (Project No. 1-440-6162). Taif University, Taif, Saudi Arabia.

Funding Statement: Funding for this study is received from Taif University Researchers Supporting Project No. (Project No. 1-440-6162), Taif University, Taif, Saudi Arabia.

Conflicts of Interest: The authors declare that they have no conflicts of interest to report regarding the present study.

\section{References}

[1] United Nations, “Ageing,” Global issues, 2019. [Online]. Available: https://www.un.org/en/global-issues/ageing/. Accessed 23 May 2021.

[2] N. Masnoon, S. Shakib, E. Kalisch-Ellett and G. Caughey, "What is polypharmacy? A systematic review of definitions," BMC Geriatr, vol. 17, no. 1, pp. 1-10, 2017.

[3] E. Peron, K. Ogbonna and K. Donohoe, "Antidiabetic medications and polypharmacy," Clinics in Geriatrric Medicine, vol. 31, no. 1, pp. 17-27, 2015.

[4] L. Midão. A. Giardini, E. Menditto, P. Kardas and E. Costa, "Polypharmacy prevalence among older adults based on the survey of health, ageing and retirement in Europe," Arch Gerontol Geriatr, vol. 78, pp. 213-220, 2018.

[5] J. M. Guzman, A. Pawliczko, S. Beales, C. Till and I. Voelcker, "Ageing in the twenty-first century: A celebration and a challenge," in HelpAge International, First edition. New York, London: United Nations Population Fund, Vol. 2, pp. 39, 2012.

[6] M. M. Fulton and E. Allen, "Polypharmacy in the elderly: A literature review," Journal of the American Association of Nurse Practitioners, vol. 17, pp. 123-132, 2005.

[7] D. Koper, G. Kamenski, M. Flamm, B. Böhmdorfer and A. Sönnichsen, "Frequency of medication errors in primary care patients with polypharmacy," Family Practice, vol. 30, pp. 313-319, 2013.

[8] S. Salih, M. Yousuf, H. Durihim, H. Almodaimegh and H. Tamim, "Prevalence and associated factors of polypharmacy among adult Saudi medical outpatients at a tertiary care centre," Journal Family and Community Medicine, vol. 20, no. 3, pp. 162-167, 2013.

[9] M. Brown and J. Bussell, "Medication adherence: WHO cares?," Mayo Clinic Proceedings, vol. 86, no. 4, pp. 304-314, 2011.

[10] A. Yap, T. Thirumoorthy and Y. Kwan, "Medication adherence in the elderly," Journal of Clinical Gerontology and Geriatrics, vol. 7, no. 2, pp. 64-67, 2016.

[11] T. Einarson, "Drug-related hospital admissions," Ann Pharmacother, vol. 27, no. 7-8, pp. 832-840, 1993.

[12] J. Mira, D. Orozco-Beltrán, V. Pérez-Jover, L. Martinez-Jimeno, V. Gil-Guillén et al., "Physician patient communication failure facilitates medication errors in older polymedicated patients with multiple comorbidities," Family Practice, vol. 30, pp. 56-63, 2013.

[13] J. Branin, "The role of memory strategies in medication adherence among the elderly," Home Health Care Services Quarterly, vol. 20, no. 2, pp. 1-16, 2001.

[14] C. Raehl, C. Bond, T. Woods, R. Patry and R. Sleeper, "Individualized drug use assessment in the elderly," Pharmacotherapy, vol. 22, no. 10, pp. 39-48, 2002.

[15] W. Weitbrecht and C. Vosskämper, "Influence of the drug package information paper on compliance of neurological and psychiatric outpatients," Fortschr Neurol Psychiatr, vol. 70, no. 1, pp. 78-84, 2002.

[16] S. Gibbs, W. Waters and C. George, "The benefits of prescription information leaflets (1)," British Journal of Clinical Pharmacology, vol. 27, no. 7, pp. 23-39, 1989. 
[17] J. Morak, M. Schwarz, D. Hayn and G. Schreier, "Feasibility of mHealth and near field communication technology-based medication adherence monitoring," Annual Int. Conf. of the IEEE Engineering in Medicine and Biology Society, vol. 272, no. 5, pp. 272-275, 2012.

[18] M. Hayakawa, Y. Uchimura, K. Omae, K. Waki, H. Fujita et al., "A smartphone-based medication selfmanagement system with realtime medication monitoring," Applied Clinical Informatics, vol. 4, no. 1, pp. 3752, 2013.

[19] E. Årsand, D. Frøisland, S. Skrøvseth, T. Chomutare, N. Tatara et al., "Mobile health applications to assist patients with diabetes: Lessons learned and design implications," Journal of Diabetes Science and Technology, vol. 6, no. 5, pp. 1197-1206, 2012.

[20] L. Dayer, S. Heldenbrand, P. Anderson, P. Gubbins and B. Martin, "Smartphone medication adherence apps: Potential benefits to patients and providers," Journal of the American Pharmacists Association, vol. 53, no. 2, pp. 172-181, 2013.

[21] O. El-Gayar, P. Timsina, N. Nawar and W. Eid, "A systematic review of IT for diabetes self-management: Are we there yet?," International Journal of Medical Informatics, vol. 82, no. 8, pp. 37-52, 2013.

[22] C. McCall, B. Maynes, C. Zou and N. Zhang, "An automatic medication self-management and monitoring system for independently living patients," Medical Engineering and Physics, vol. 35, no. 4, pp. 505-514, 2013.

[23] N. Tatara, E. Arsand, S. Skrøvseth and G. Hartvigsen, "Long-term engagement with a mobile self-management system for people with type 2 diabetes," JMIR Mhealth and Uhealth, vol. 1, no. 1, pp. 1-19, 2013.

[24] J. Mira, L. Ortiz, S. Lorenzo, C. Royuela, J. Vitaller et al., "Oversights, confusions, misinterpretations and errors that influence treatment safety in diabetic patients or those with kidney failure," Medical Principles and Practice, vol. 23, no. 3, pp. 246-252, 2014.

[25] P. Kubben, "QR codes in neurosurgery," Surgical Neurology International, vol. 2, no. 104, pp. 1-2, 2011.

[26] P. Fontelo, F. Liu and E. Ducut, "QR code for medical information uses," in AMIA Annual Symposium Proc., Washington DC, vol. 6, no. 945, 2008.

[27] M. Fischer, D. Rybitskiy, G. Strauß, A. Dietz and C. Dressler, "QR-Code based patient tracking: A cost-effective option to improve patient safety," Laryngorhinootologie, vol. 92, no. 3, pp. 170-175, 2013.

[28] M. Naagaraj, "Implementing QR code technology in medical device package," Ph.D. dissertation, Rochester Institute of Technology, United States, 2009.

[29] D. Sethia, D. Gupta, T. Mittal, U. Arora and H. Saran, "NFC based secure mobile healthcare system," in Proc. of the IEEE Sixth Int. Conf. on Communication Systems and Networks, Basel, Switzerland, pp. 106, 2014.

[30] T. Yoon and J. Lee, "Development of system NFC-based medication management for elderly patients," Journal of the Korea Academia -Industrial Cooperation Society, vol. 15, pp. 5303-5309, 2014.

[31] N. Razmi and A. Sangar, "The use of NFC technology to record medical information in order to improve the quality of medical and treatment services," Modern Applied Science, vol. 10, no. 136, pp. 136-141, 2016.

[32] J. Fontecha, F. Navarro, R. Hervás and J. Bravo, "An NFC approach for nursing care training," in Third Int. Workshop on Near Field Communication, Hagenberg, pp. 38-43, 2011.

[33] R. Holden, R. Brown, M. Scanlon and B. Karsh, "Modeling nurses' acceptance of barcoded medication administration technology at a pediatric hospital," Journal of the American Medical Informatics Association, vol. 19, no. 6, pp. 1050-1058, 2012.

[34] J. Romero, "No more waiting on near field communication," IEEE Spectrum, vol. 49, no. 6, pp. 64-64, 2012. 